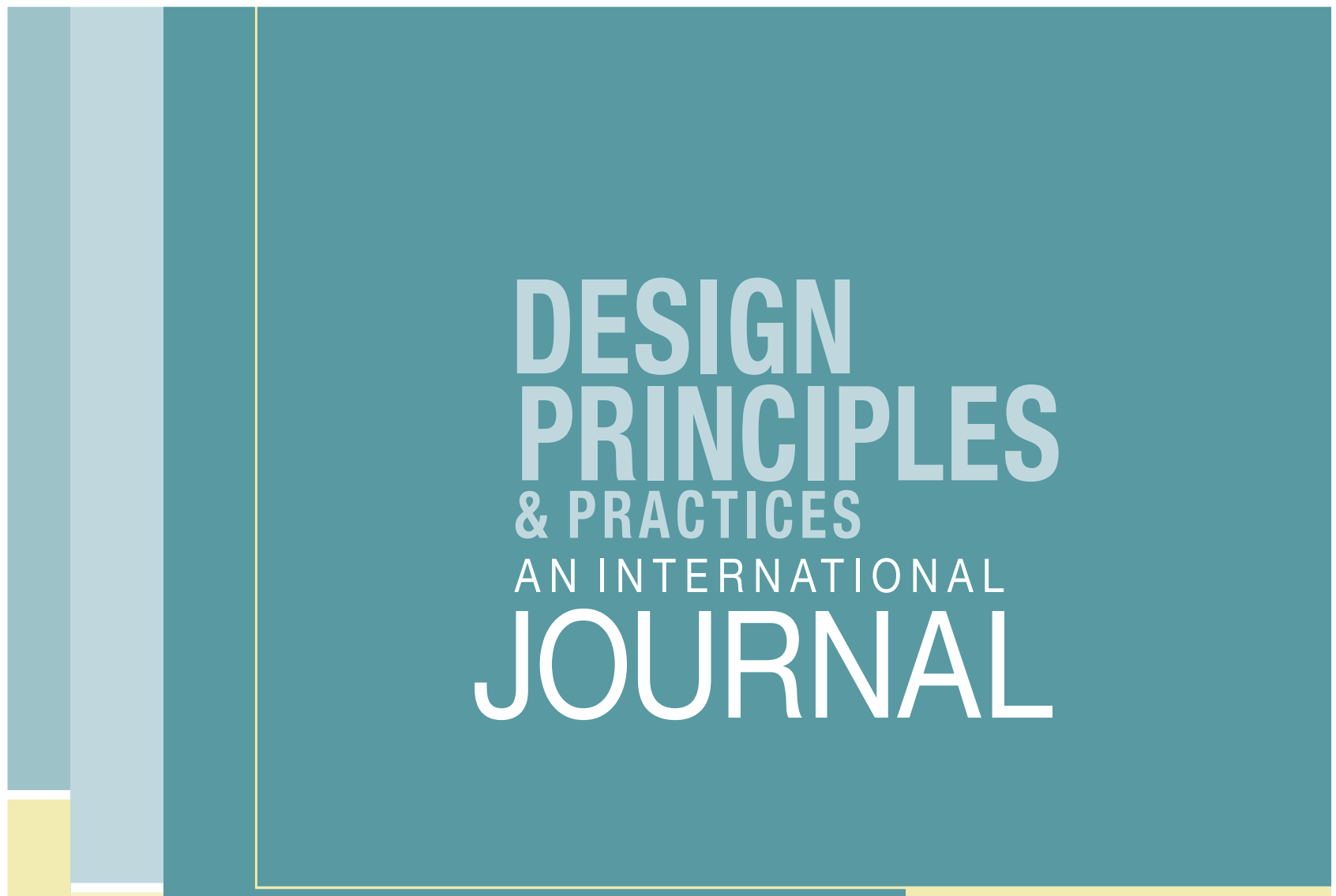

Volume 4, Number 4

A Quantitative Comparison between Wright's Prairie Style and Triangle-Plan Usonian Houses using Fractal Analysis

Josephine Vaughan and Michael J. Ostwald 
DESIGN PRINCIPLES AND PRACTICES: AN INTERNATIONAL JOURNAL http://www.Design-Journal.com

First published in 2010 in Champaign, Illinois, USA by Common Ground Publishing LLC www.CommonGroundPublishing.com.

(C) 2010 (individual papers), the author(s)

(C) 2010 (selection and editorial matter) Common Ground

Authors are responsible for the accuracy of citations, quotations, diagrams, tables and maps.

All rights reserved. Apart from fair use for the purposes of study, research, criticism or review as permitted under the Copyright Act (Australia), no part of this work may be reproduced without written permission from the publisher. For permissions and other inquiries, please contact

<cg-support@commongroundpublishing.com>.

ISSN: 1833-1874

Publisher Site: http://www.Design-Journal.com

DESIGN PRINCIPLES AND PRACTICES: AN INTERNATIONAL JOURNAL is peerreviewed, supported by rigorous processes of criterion-referenced article ranking and qualitative commentary, ensuring that only intellectual work of the greatest substance and highest significance is published.

Typeset in Common Ground Markup Language using CGCreator multichannel typesetting system

http://www.commongroundpublishing.com/software/ 


\title{
A Quantitative Comparison between Wright's Prairie Style and Triangle-Plan Usonian Houses using Fractal Analysis
}

\author{
Josephine Vaughan, The University of Newcastle, NSW, Australia \\ Michael J. Ostwald, The University of Newcastle, NSW, Australia
}

\begin{abstract}
In recent years a computational variation of the "box-counting method" has been developed that can produce objective and quantitative determinations of the visual complexity of buildings. Ongoing research to test the validity of this computational method has produced more than 30 sets of consistent data representing the work of several historically significant architects including Eileen Gray, Le Corbusier, Kazuyo Sejima and Peter Eisenman. These results suggest that the box-counting method is potentially significant and that its computational variation merits further testing and exploration. Past research using this method has typically focused on sets of works, produced as part of a consistent stylistic period in an architect's career. This research typically showed significant clustering of the characteristic complexity, or fractal dimension, of various architect's designs. If this is true, then the method may be useful for differentiating particular stylistic periods in an architect's career. In order to test this possibility, the present paper undertakes a comparison between the visual complexity of five of Frank Lloyd Wright's Triangle-Plan Usonian houses and five of Wright's Prairie houses. Through this comparison of the fractal dimensions of both the elevations and plans of these ten buildings it may be possible to quantify the formal differences between these two periods in the architect's oeuvre.
\end{abstract}

Keywords: Computational Analysis, Design Tools, Frank Lloyd Wright, Visual Complexity

\section{Introduction}

$\mathrm{I}$ NSPIRED BY THE non-linear mathematics of Benoit Mandelbrot (1982), in 1996 Carl Bovill published Fractal geometry in architecture and design in which he demonstrated that the elevations of famous buildings could be analysed using the "box-counting" method to calculate the approximate fractal dimension of a façade. The fractal dimension, or $D$, of an image is a non-integer value between 1.0 and 2.0 which indicates the characteristic visual complexity of an object. A comparison between the $D$ values of different architects' works is potentially an important tool in architectural design and computational analysis. As one of a limited range of quantifiable approaches to the analysis of the visual qualities of buildings and landscapes, this computational method can potentially assist architects to create buildings which can contribute toward studies of visual preference and also help to determine the "contextual fractal fit" of buildings into particular locations (Stamps III 2002). In the last few years a computational variation of Bovill's manual method has been developed and consistently tested for a large number of examinations of historic buildings (Lorenz 2003; Ostwald, Vaughan, Chalup 2008; Vaughan and Ostwald 2008).

Design Principles and Practices: An International Journal C $O M M O N$

Volume 4, Number 4, 2010, http://www.Design-Journal.com, ISSN 1833-1874 $G \quad R \quad U N D$ (C) Common Ground, Josephine Vaughan, Michael J. Ostwald, All Rights Reserved, Permissions: cg-support@commongroundpublishing.com 
Significantly, this previous analysis has been focused almost exclusively on elevations, and not plans, of buildings.

The present research undertakes a comparative analysis of the fractal dimensions of two defining periods of Frank Lloyd Wright's architectural career. In each part of his career, five of his free-standing house designs are subjected to analysis. The first five of Wright's early house designs in this study were completed between 1901 and 1910 and are from his Prairie Style period; regarded by some critics as "Wright's greatest invention in this first phase of a long career"(Kostof 1985:684). A fractal dimension calculation, to two decimal places, for the $D$ values of these houses was previously published by Ostwald, Vaughan, Tucker (2008) along with a detailed description of the method. In the present paper the same raw data is used for the Prairie period although it is now recalculated to three or more decimal places; giving a more accurate result. In addition to this increased accuracy, the plans for the selected Prairie Houses have also been included in the analysis for the first time. In parallel, a completely new analysis of five of Wright's houses from his "Triangle-Plan" Usonian period is undertaken for comparative purposes. These houses, which were completed between 1950 and 1955 represent a "continuation of [Wright's] lifelong quest to destroy boxlike rooms" (Lind 1994:9). During his lengthy career Wright pioneered many architectural design strategies for housing. These two distinct periods, separated by 40 years, mark significant early and late eras in Wright's domestic architecture. By comparing the results from these two periods the present paper suggests that not only is fractal analysis useful for defining the characteristics of a single architect's work, but it may also be a significant way of identifying different periods in an architect's career.

This paper commences with an overview of Wright's Prairie style and Triangle-Plan Usonian periods. Thereafter, the paper provides a brief description of the box-counting method for fractal analysis and describes how the present study was undertaken. The paper concludes with a review of the new results of the study of the Triangle-Plan houses, and a comparison with the previous results of Wright's Prairie houses.

\section{Frank Lloyd Wright and the Ten Houses}

Frank Lloyd Wright is one of the most important architects of the 20th Century. Anthony Alofsin describes him as "America's most celebrated architect" and as being responsible for creating a "revolution in domestic architecture" (2004: 281). Wright pioneered an enduringly popular, alternative version of modern architecture that, according to Pfeiffer, "would change the face of architecture in the world" (2004:13). Such is Wright's legacy that his works are still analysed in depth today, with hundreds of books and thousands of scholarly papers being published on his architecture, theories, principles and texts. However, the vast majority of the published research consists of qualitative interpretations of Wright's architecture, with only a comparatively small amount of quantitative analysis of Wright's work in existence, so that, according to Laseau and Tice, Wright is "the best known and least understood of American architects" (1992: ix).

The existing diverse collection of qualitative analysis based on primary sources of Wright's designs and writings are largely subjective. The existing buildings and extensive collection of Wright's designs are available, but their interpretation has been approached by various methodologies, resulting in different assumptions about his work. Likewise, concerning Wright's published writings, Gerald Nordland suggests that 
[t]he precision and grace of Frank Lloyd Wright's architecture are rarely to be found in his writing. He wrote swiftly and with ardour, and although he revised some pieces from time to time, his ideas were so large and encompassing that he found it sufficient if his words conveyed their general shape or effect. (1988:4)

This characteristic of Wright's work makes it possible for qualitative scholarly conclusions to differ, as it would be possible for one paragraph written by Wright to be interpreted in many ways.

The present paper considers the formal and visual qualities of Wright's works using a computational or quantitative method, rather than a traditional historical or theoretical method. As identified by Laseau and Tice, past scholarly

emphasis has been on the symbolic meaning of [Wright's] architecture rather than on an understanding of its intrinsic formal structure. The assumed split between idea and form, with the higher valuation usually given to the former, has made achieving the necessary connection between the two more difficult. (1992: 1)

The small number of quantitative studies on Wright's designs that have been published confirm that it is not only possible to study Wright's architecture using computational means, but it is highly beneficial because of the size of the body of work he produced. Of similar importance is the fact that several of the computational or geometric studies of Wright's architecture that have previously been undertaken have been focused on his houses.

While not a computational study, an interesting case exists of an attempt to uncover fractalesque qualities of Wright's domestic architecture. Leonard Eaton (1998) defines a fractal as "a geometrical figure in which an identical motif repeats itself on an ever diminishing scale" (33). Eaton suggests that Wright's work became more visually complex, or more fractal, after 1923 or in the years after the design of the Textile block house La Miniatura; a building which Eaton feels has no strong fractal presence. By comparison, Eaton suggests that Wright's work of the 1950's and 1960's, his Usonian period, suggests a "striking anticipation of fractal geometry" (1998:31). Eaton's method of analysis involves identifying self-similar equilateral triangles in the plan of Wright's Palmer House (Figure 1). Details ranging from the triangular slabs of the cast concrete floors down to the triangular shape of the fire iron rest are noted. Eaton counts "no less than eleven scales of equilateral triangles ascending and descending from the basic triangle" (1998:32) leading him to conclude that the Palmer House has "a three-dimensional geometry of bewildering complexity" (1998:35). Yannick Joye agrees with Eaton's assertion that the "Palmer House seems to be the culmination point" (2007:312) of Wright's intuitive use of fractal geometry in architecture. 


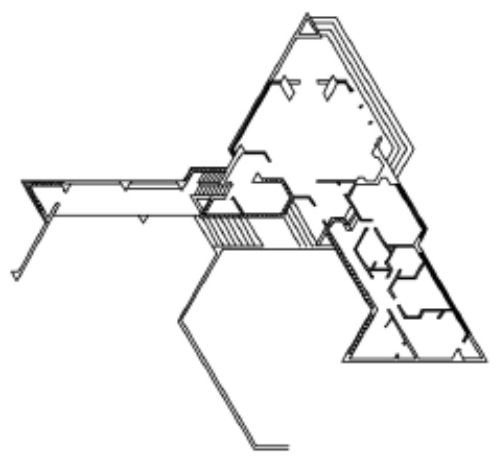

Figure 1: Palmer House Plan

\section{Prairie Style}

The five Prairie Style houses by Wright were constructed between 1901 and 1910. Four of the five are in the state of Illinois and the fifth is in Kentucky. All of the houses are characterized by strong horizontal lines, overhanging eaves, low-pitched roofs, open floor plan and a central hearth. Kostof remarks that in these houses "[o]rnament as such we do not find: only the prismatic interlocking of crisp planes and some abstract patterning" (1985:684). Importantly, the five houses span the period between the first publication of Wright's Prairie Style, in the Ladies Home Journal in 1901, and what is widely regarded as the ultimate example of this approach, the Robie house (Figure 2). The first Prairie Style design is the F. B. Henderson House in Elmhurst, Illinois which was completed in 1901. The house is a wooden, two-storey structure with plaster rendered elevations. A range of additions were made to the house in the years following its completion until, in 1975, the house was restored to its original form. The Tomek House, completed in 1907, in Riverside, Illinois, is also a two-storey house although it possesses a basement and is sited on a large city lot (Figure 2). This house is finished with pale, rendered brickwork, dark timber trim and a red tile roof. Storrer (1993) notes that, in response to the Tomek family's needs, Wright later allowed posts to be placed beneath the cantilevered roof to heighten the sense of support and enclosure. As the posts were not required for structural reasons, and Wright found them personally unnecessary, they have been omitted from the analysis. The Robert W. Evans House, completed in Chicago, Illinois in 1908, features a formal diagram wherein the "basic square" found in earlier Prairie Style houses is "extended into a cruciform plan" (Thomson 1999, 100). The house is set on a sloping site and possesses a plan similar to one Wright proposed in 1907 for a "fireproof house for \$5000". The Evans house was later altered to enclose the porch area and the stucco finish on the façade was also cement rendered. The Zeigler House in Frankfort, Kentucky was constructed in 1910 and has a similar plan to the Evans house. Designed as a home for a Presbyterian minister, this two-storey house is sited on a small, city lot and it was constructed while Wright was in Europe. After a decade of development and refinement the quintessential example of the Prairie Style, the Robie House was constructed in Chicago, Illinois in 1910. Designed as a family home, the three storey structure fills most of its corner site. Unlike many of Wright's other houses of the era, the Robie house features a façade of exposed, raked bricks. 

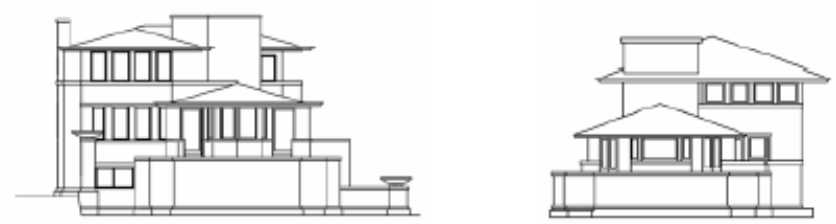

Figure 2: Prairie House Set; Robie House, Elevation 4 (Left) Tomek House, Elevation 3 (Right)

\section{Usonian Style}

More than forty years were to pass before Wright developed his third major sequence of domestic works; the Usonian houses. Wright (1954) explains that the Usonian house is intended to be

[...] integral to the life of the inhabitants [and] the nature of materials - wherein glass is used as glass, stone as stone, wood as wood - and all the elements of environment go into and throughout the house. Into this new integrity, once there, those who live in it will take root and grow. And most of all belonging by nature to the nature of its being. (353)

Hoffman describes the Usonian house as "a simplified and somewhat diluted prairie house characterized by the absence of leaded glass and the presence of [...] very thin wall screens with a striated effect from wide boards spaced by recessed battens" $(1995,80)$. While there were multiple variations on the Usonian house, the five chosen houses are differentiated from other houses in the period by being based on a 4' equilateral triangle grid plan. According to Pyron, who describes this as the "diamond module", this was for Wright,

[...] a simple system of designing a house so that all angles were 60 or 120 degrees. In designing such a house, he first drew modular lines parallel to each other. These lines were often drawn on a four foot scale so that in the completed house they would appear exactly four feet apart. In the concrete floor of the house these modular lines become expansion joints. Next, he drew other parallel lines intersecting the first lines at 120 degree angles. Thus, all angles in the modular system become 60 and 120 degree angles. The diamond module [...] can be seen as two equilateral triangles joined to form a diamond shape. (1961:95)

The five houses selected for analysis were all constructed between 1950 and 1956. The first of the triangle-plan Usonian Houses, the William Palmer House is located in Ann Arbour, Michigan and was completed in 1950. The house is a two-storey brick structure, set into a sloping site, with wide, timber-lined eaves, giving the viewer an impression of a low, single level house. The brick walls include bands of patterned, perforated blocks, in the same colour as the brickwork. The second house, the Reisley Residence was the last of Wright's Usonian houses built in Pleasantville, New York; it was completed in 1951 (Figure 3). This single level home with a small basement is constructed from local stone with timber panelling and 
is set on a hillside site. To accommodate the Reisley's expanding family, five years later Wright designed an addition for the children's bedrooms. In contrast in the same year the Chahroudi Cottage was built on an island in Lake Mahopac, New York, and constructed using Wright's desert masonry rubblestone technique with some timber cladding and detailing. The cottage was originally designed by Wright as the guest quarters for the Chahroudi family home however, only the cottage was built and subsequently used as the primary residence (Figure 3). The Dobkins House was built in 1953 for Dr John and Syd Dobkins in Canton, Ohio. This small house is constructed from brick with deeply raked mortar joints. However, unlike the Robie house, the mortar colour contrasts with the bricks in the vertical as well as the horizontal joints. Finally, the Fawcett Residence, completed in 1955, had an unusual brief for Wright to design a home for a farming family. The house is set on the large flat expanse of the Fawcett's walnut farm in Los Banos, California. The single storey house is constructed primarily of grey concrete block with a red gravel roof.

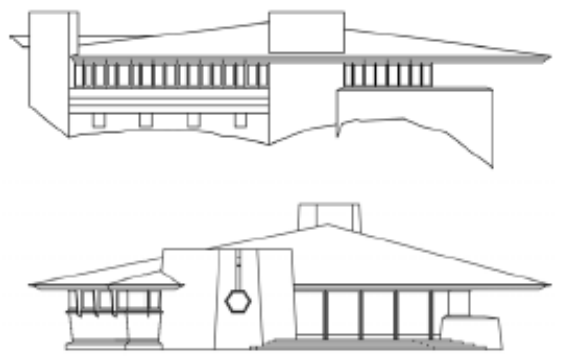

Figure 3: Triangle-Plan Usonian Set; Reisley House, Elevation 4 (Top). Chahroudi House, Elevation 1 (Bottom)

\section{Box Counting}

The box-counting approach is one method for determining the approximate fractal dimension of an image. The method commences with a drawing of an elevation of a house. A large grid is placed over the drawing and each square in the grid is analysed to determine whether any lines from the façade are present in each square. Those grid boxes that have some detail in them are recorded. Next, a grid of smaller scale is placed over the same façade and the same determination is made of whether detail is present in the boxes of the grid. A comparison is then constructed between the number of boxes with detail in the first grid and the number of boxes with detail in the second grid; this comparison is made by plotting a loglog diagram for each grid size (Bovill, 1996; Lorenz, 2003). By repeating this process over multiple grids of different scales, an estimate of the fractal dimension of the façade is produced. While this process can be done by hand, the software programs Benoit and Archimage automate and refine this operation.

There are many variations of the box-counting approach that respond to known deficiencies in the method. These issues include preparation of the original image for analysis, with regard for the volume of empty space, the proportion of the image and the thickness of the lines. Other reasons for problematic results derive from elements of the method including the scaling coefficient, and statistical divergence in the log-log graph. Past research papers have 
described how the current computational method responds to each issue or minimizes their impact (Ostwald, Vaughan, Tucker 2008).

\section{Method}

For the present paper, the data for the previously analysed Prairie Houses is reproduced and augmented with new drawings of the complete set of plans for each of the five Prairie Houses. This present paper analyses all floor plans for each of the ten houses, producing results for 18 plans. Most of Wright's Prairie Style houses are multi-storey, while the triangle-plan Usonian houses analysed are all single storey with the exception of the Reisley House. New drawings with consistent graphic conventions and scale were prepared for analysis of elevations and plans of each of the five Triangle-Plan houses. Due to the triangular nature of the planning of these buildings, the Fawcett and Chahroudi houses only have three distinct elevations which could be analysed. For the other three houses (Palmer, Dobkins, and Reisley) four elevations were produced for testing. The lines in each drawing typically record changes in form, not changes in surface or texture. Thus, major window reveals, thickened concrete edge beams and railings are all drawn, while the cracks in stone blocks and the patterns embedded in the stucco textures are not. The extensive collections of Wrights work published by Bruce Brooks Pfeiffer, including the Frank Lloyd Wright Monograph and Frank Lloyd Wright: Elegant houses were adopted as the source for all images analysed in this paper (Pfeiffer 1988, 2002).

The standard method for the fractal analysis of visual complexity in houses involves analysing the redrawn images with Archimage and Benoit software. Archimage is a program that has been optimized for the analysis of the fractal dimension of architectural images. Benoit is a stable, commercial software tool that is used in the testing to provide a comparison for the Archimage results, ensuring consistency. The $D_{\text {(Archi) }}$ and $D$ (Benoit) results for the elevation views are then averaged together to produce a separate $D$ (Elev) result for each facade of the house. Past research suggests that $D_{\text {(Elev) }}$ results tend to be relatively tightly clustered leading to a high degree of consistency. Next, the $D_{(\text {Elev }}$ results are averaged together to produce a composite result, $D_{(\mathrm{Comp})}$, for the house. The composite result is a single $D$ value that best approximates the characteristic visual complexity of the house. Finally, if there are a set of five houses by an architect being considered, the $D_{\text {(Comp) }}$,results are averaged together to produce an aggregate for the architect's works; $D_{(\mathrm{Agg})}$.

Bovill (1996) suggests that it may be useful to compare the $D$ results for the plans and elevations of buildings but this suggestion has not previously been undertaken in any systematic way. The present paper not only includes plan results for the buildings $\left(D_{\text {(Plan) }}\right)$, but it produces one set of figures where these results are combined with those for elevations $(D$ (Elev) $)$, to produce a single result; $D$ (Plan + Elev) . While this result might be seen as artificial, it could nevertheless be argued to reflect both the two and three dimensional qualities of the building's form. It is important to note that this is not the same as calculating the $D$ of the three dimensional building, it is instead a process reliant on the average two dimensional $D$ properties in both elevations and plans.

One of the reasons this variation, measuring the $D$ values of plans, has not been systematically followed in the past is that elevations are conventionally regarded as the primary determinants of visual character while plans are more experiential. Because the method measures visual complexity, the argument has always been stronger to focus only on elevations, even 
if, the relationship, if any, between plans and elevations remains an interesting question. Thus the present paper includes both the standard comparison on the basis of $D_{\text {(Elev) }}$ results as well as the less common $D_{\text {(Plan + Elev). }}$

\section{Table 1: Abbreviations and Definitions}

\begin{tabular}{|l|l|}
\hline Abbreviation & Meaning \\
\hline$D$ & Approximate Fractal Dimension. \\
\hline$D_{\text {(Archi) }}$ & $D$ calculated using Archimage software \\
\hline$D_{\text {(Benoit) }}$ & $D$ calculated using Benoit software. \\
\hline$D_{\text {(Elev) }}$ & Average $D$ for a set of elevation views of a house using a specified program. \\
\hline$D_{\text {(Plan) }}$ & Average $D$ for a set of plans of a house using a specified program. \\
\hline$D_{\text {(Plan }+ \text { Elev) }}$ & $\begin{array}{l}\text { Average } D \text { for a combined set of elevations and plans of a house using a } \\
\text { specified program }\end{array}$ \\
\hline$D_{\text {(Comp) }}$ & $\begin{array}{l}\text { Composite D result (averaged from both Archimage and Benoit outcomes } \\
\text { for all elevations) is a measure of the average characteristic visual complex- } \\
\text { ity of the house (or average fractal dimension for the 2D visual qualities } \\
\text { of the design). }\end{array}$ \\
\hline$D_{\text {(Agg) }}$ & $\begin{array}{l}\text { Aggregated result of five composite values used for producing an overall } \\
D \text { for a set of architects' works. }\end{array}$ \\
\hline
\end{tabular}

\section{Results}

For the five Prairie House houses, a total of 20 elevations produced 480 data points, and an aggregate result for Frank Lloyd Wright's Prairie Houses was found to be $D_{(\mathrm{Agg})}=1.543$ (Ostwald, Vaughan, Tucker 2008). The new calculations for the 12 plans of the five Prairie Houses provided an average of $D_{\text {(Agg Plan) }}=1.4701$ and the overall average of all plans and elevations of the Prairie Houses $D$ (Agg Plan+Elev) $=1.4426$. The new calculations for the Triangle-Plan Usonian houses were undertaken on 18 elevations of the five houses producing 468 data points, providing the aggregate result for the visual complexity of Frank Lloyd Wright's Triangle Plan house elevations as $D_{(\mathrm{Agg})}=1.425$. The calculations of the 6 plans of the Triangle Plan houses result in an average of $D_{\text {(Agg Plan) }}=1.4074$ and the overall average of all plans and elevations of the Triangle Plan Houses $D$ (Agg Plan+Elev) $=1.4151$.

The results for the elevations of five Triangle-Plan Usonian houses provide $D_{(\mathrm{Comp})}$ values ranging from a low of $D_{(\mathrm{Comp})}=1.350$ for the Fawcett House, to a high of $D_{(\mathrm{Comp})}=1.486$ for the Palmer House (see table 2). The low result is produced by elevations 1 and 3 of the Fawcett House which are relatively low in comparison to the other five houses and elevation 3 of this house which has the lowest fractal dimension for all of the five houses ( $D_{\text {(Elev, Archi) }}$ $=1.290)$. The rest of the houses generally have higher fractal dimensions results than the Fawcett house. For example, all the elevations for Palmer (see figure 4) and Dobkins display higher visual complexity, with elevation 2 (south west) of the Dobkins house returning the highest $D$ result for an individual elevation in this set of houses; $D_{\text {(Elev, Archi) }}=1.582$. 


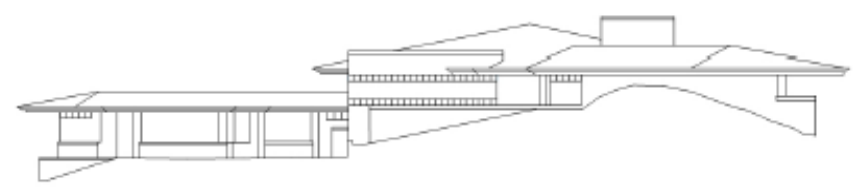

Figure 4: The Palmer House South East Elevation

Table 2: D Values for the Elevations of the Five Triangle-Plan Usonian Houses

\begin{tabular}{|c|c|c|c|c|c|c|c|c|c|}
\hline \multirow[b]{2}{*}{ House } & \multicolumn{4}{|c|}{$\begin{array}{l}\text { Elevations Analysed with } \\
\text { Archimage }\end{array}$} & \multicolumn{4}{|c|}{$\begin{array}{l}\text { Elevations Analysed with } \\
\text { Benoit }\end{array}$} & \multirow[b]{2}{*}{$\begin{array}{l}D \\
\text { (Comp) }\end{array}$} \\
\hline & $\begin{array}{l}D \\
(\text { Elev }) \\
1\end{array}$ & $\begin{array}{l}D \\
(\text { Elev })^{2}\end{array}$ & $\begin{array}{l}D \\
(\text { Elev })^{3}\end{array}$ & $\begin{array}{l}D \\
(\text { Elev })^{4}\end{array}$ & $\begin{array}{l}D \\
(\text { Elev })\end{array}$ & $\begin{array}{l}D \\
(\text { Elev })^{2}\end{array}$ & $\begin{array}{l}D \\
(\text { Elev })^{3}\end{array}$ & $\begin{array}{l}D \\
(\text { Elev })^{4}\end{array}$ & \\
\hline Palmer & 1.543 & 1.520 & 1.542 & 1.559 & 1.418 & 1.419 & 1.428 & 1.452 & 1.486 \\
\hline Reisley & 1.446 & 1.446 & 1.441 & 1.477 & 1.435 & 1.432 & 1.429 & 1.440 & 1.434 \\
\hline Chahroudi & 1.536 & 1.560 & 1.486 & - & 1.396 & 1.422 & 1.435 & - & 1.403 \\
\hline Dobkins & 1.426 & 1.582 & 1.449 & 1.500 & 1.322 & 1.460 & 1.351 & 1.446 & 1.442 \\
\hline Fawcett & 1.379 & 1.494 & 1.290 & - & 1.314 & 1.362 & 1.259 & - & 1.350 \\
\hline
\end{tabular}

The result of the plans for the five Triangle-Plan Usonian houses (see table 3) show the Reisley house having the lowest $D$ (Comp, Plan) $=1.3657$, and the Chahroudi producing the highest, with $D$ (Comp, Plan) $=1.4891$. The results for the plans and elevations do not align closely, with the levels of complexity in the plans of the Fawcett House being much higher than the general low levels in the elevations.

Table 3: D Values for the Plans of the Five Triangle-Plan Usonian Houses

\begin{tabular}{|c|c|c|c|c|c|c|c|c|}
\hline \multirow[b]{2}{*}{ House } & \multicolumn{3}{|c|}{$\begin{array}{l}\text { Plans Analysed with } \\
\text { Archimage }\end{array}$} & \multicolumn{3}{|c|}{$\begin{array}{l}\text { Plans Analysed with } \\
\text { Benoit }\end{array}$} & \multirow[b]{2}{*}{\begin{tabular}{|l}
$D$ \\
(Comp, \\
Plan) \\
\end{tabular}} & \multirow[b]{2}{*}{\begin{tabular}{|l}
$D$ \\
(Comp, \\
Plan+Elev) \\
\end{tabular}} \\
\hline & $\begin{array}{l}D \\
\text { (Plan) } 1\end{array}$ & $\begin{array}{l}D \\
(\text { Plan) }\end{array}$ & $\begin{array}{l}D \\
(\text { Plan })^{3}\end{array}$ & $\begin{array}{l}D \\
\text { (Plan) } 1\end{array}$ & $\begin{array}{l}D \\
\text { (Plan) } 2\end{array}$ & $\begin{array}{l}D \\
(\text { Plan) }\end{array}$ & & \\
\hline Palmer & 1.414 & - & - & 1.405 & - & - & 1.4095 & 1.4477 \\
\hline Reisley & 1.399 & 1.376 & - & 1.360 & 1.328 & - & 1.3657 & 1.3998 \\
\hline Chahroudi & 1.536 & - & - & 1.442 & - & - & 1.4891 & 1.4460 \\
\hline Dobkins & 1.406 & - & - & 1.347 & - & - & 1.3765 & 1.4092 \\
\hline Fawcett & 1.416 & - & - & 1.377 & - & - & 1.3965 & 1.3732 \\
\hline
\end{tabular}

The result of the plans for the five Prairie Houses (see table 4) show the Zeigler house having the lowest $D$ (Comp, Plan) $=1.435$, and the Henderson House producing the highest, with $D$ (Comp, Plan) $=1.5027$. 
Table 4: D Values for the Plans of the Five Prairie Houses

\begin{tabular}{|c|c|c|c|c|c|c|c|c|}
\hline \multirow[b]{2}{*}{ House } & \multicolumn{3}{|c|}{$\begin{array}{l}\text { Plans Analysed with } \\
\text { Archimage }\end{array}$} & \multicolumn{3}{|c|}{$\begin{array}{l}\text { Plans Analysed with } \\
\text { Benoit }\end{array}$} & \multirow[b]{2}{*}{\begin{tabular}{|l}
$D$ \\
(Comp, \\
Plan) \\
\end{tabular}} & \multirow[b]{2}{*}{\begin{tabular}{|l}
$D$ \\
(Comp, \\
Plan+Elev) \\
\end{tabular}} \\
\hline & $\begin{array}{l}D \\
\text { (Plan) } 1\end{array}$ & $\begin{array}{l}D \\
\text { Plan)2 }\end{array}$ & $\begin{array}{l}D \\
(\text { Plan) }\end{array}$ & $\begin{array}{l}D \\
\text { (Plan) } 1\end{array}$ & $\begin{array}{l}D \\
\text { (Plan) } 2\end{array}$ & $\begin{array}{l}D \\
(\text { Plan) }\end{array}$ & & \\
\hline Henderson & 1.503 & 1.468 & - & 1.450 & 1.381 & - & 1.5027 & 1.4752 \\
\hline Tomek & 1.489 & 1.498 & 1.505 & 1.491 & 1.417 & 1.447 & 1.4661 & 1.4329 \\
\hline Zeigler & 1.437 & 1.499 & - & 1.400 & 1.401 & - & 1.435 & 1.4405 \\
\hline Evans & 1.514 & 1.519 & - & 1.442 & 1.463 & - & 1.483 & 1.4461 \\
\hline Robie & 1.441 & 1.513 & 1.535 & 1.390 & 1.483 & 1.422 & 1.4638 & 1.4185 \\
\hline
\end{tabular}

When the results for the Triangle-Plan houses are compared to the previously recorded results for the earlier Prairie houses, the Triangle-Plan houses are consistently lower in both elevation and plan calculations, and the aggregate values reflect this (see Table 5). This means that the Triangle-Plan houses typically have less visual complexity than Wright's Prairie Houses. These results match the historical analysis of these buildings, as Wright's architectural skills became more refined and his houses less formally expressive.

The results partially support Eaton's proposal that The Palmer house is highly complex. The results for the Palmer house in elevation show it is more complex than the other TrianglePlan houses analysed, however, it has a lower fractal dimension than any of the elevations of the Prairie Houses. Eaton specifically focused on the fractal nature of the plans of the Palmer house, however the results show the Palmer house to be only the second most visually complex of the Triangle-Plan houses studied in plan, and with a lower fractal dimension than any of the plans of the Prairie Houses.

Table 5: $\mathbf{D}_{(\text {Comp) }}$ Values for all Frank Lloyd Wright Houses Analysed

\begin{tabular}{|l|l|l|l|}
\hline Houses (1901-1910) & $D_{\text {(Comp, Elev) }}$ & Houses (1950-1959) & $D_{\text {(Comp, Elev) }}$ \\
\hline Henderson & 1.545 & Palmer & 1.486 \\
\hline Tomek & 1.535 & Reisley & 1.443 \\
\hline Zeigler & 1.505 & Chahroudi & 1.403 \\
\hline Evans & 1.580 & Dobkins & 1.442 \\
\hline Robie & 1.550 & Fawcett & 1.350 \\
\hline$D_{\text {(Agg Elev) }}$ & 1.543 & $D_{\text {(Agg Elev) }}$ & 1.425 \\
\hline
\end{tabular}




\begin{tabular}{|l|l|l|l|}
\hline & $D_{(\text {Comp, Plan) }}$ & & $D_{(\text {Comp, Plan })}$ \\
\hline Henderson & 1.5027 & Palmer & 1.4095 \\
\hline Tomek & 1.4661 & Reisley & 1.3657 \\
\hline Zeigler & 1.435 & Chahroudi & 1.4891 \\
\hline Evans & 1.483 & Dobkins & 1.3765 \\
\hline Robie & 1.4638 & Fawcett & 1.3965 \\
\hline$D_{\text {(Agg. Plan) }}$ & 1.4701 & $D_{\text {(Agg. Plan) }}$ & 1.4074 \\
\hline
\end{tabular}

\section{Conclusion}

The present paper contains three original outcomes. First, the results for the elevations and plans for five of Wright's Triangular-Plan Usonian houses are presented here for the first time. These results are now available for other scholars to test or use in new studies of Wright, fractal analysis and visual complexity. Secondly, the set of five Prairie Houses analysed using fractal analysis are now complete, with all plans now included in the data. The third important outcome is that this paper demonstrates that the computational method for the analysis of characteristic visual complexity can be used to differentiate periods in an architect's oeuvre, in much the same way that an analysis of formal approaches or shape grammars potentially can. While further research is needed to analyse the difference between these two sets of results, and possibly seek the inclusion of additional houses from between these eras, the means by which these two sets can be seen to mathematically differ remains significant.

\section{Acknowledgements}

This research was undertaken with the support of an ARC Discovery Grant: DP0770106.

\section{References}

Alofsin, Anthony. (2004). "Wright, influence, and the world at large." in American architectural history: a contemporary reader, edited by Keith Eggner, New York: Routledge, 281-293.

Birk, M. (1998). Frank Lloyd Wright and the Prairie. New York: Universe Publishing.

Bovill, C. (1996). Fractal Geometry in Architecture and Design. Boston: Birkhäuser.

Eaton, Leonard. (1998). "Fractal Geometry in the Late Work of Frank Lloyd Wright." in Nexus II: Architecture and Mathematics, edited by Kim Williams, Fucecchio (Florence): Edizioni dell'Erba, 23-38.

Joye, Yannick. (2007). "Fractal Architecture Could Be Good for You." Nexus Network Journal 9, 311320.

Kostof, S. (1985). A History of Architecture: Settings and Rituals New York: Oxford University Press. Laseau, Paul, and James Tice. (1992). Frank Lloyd Wright: Between Principle and Form. New York: Van Nostrand Reinhold.

Lind, C. (1994). Frank Lloyd Wright's Usonian Houses. San Francisco: Pomegranate.

Lorenz, W. (2003). "Fractals and Fractal Architecture". Masters Diss, in http://www.iemar.tuwien.ac.at/modul23/Fractals/. Vienna University of Technology.

Mandelbrot, B. (1982). The Fractal Geometry of Nature. San Francisco: WH Freeman and Company. 
Nordland, Gerald. (1988). "Introduction." in Frank Lloyd Wright in the Realm of Ideas, edited by Bruce Brooks Pfeiffer and Gerald Nordland. Carbondale: Southern Illinois University Press, $1-4$.

Ostwald, M, J., J. Vaughan, and S. Chalup. (2008). “A Computational Analysis of Fractal Dimensions in the Architecture of Eileen Gray" in A. Kudless, N. Oxman and M. Swackhamer (eds), ACADIA 08: Silicon + Skin: Biological Process and Computation. Acadia, Minneapolis, $256-263$.

Ostwald, M. J., J. Vaughan, and C. Tucker. (2008). "Characteristic Visual Complexity: Fractal Dimensions in the Architecture of Frank Lloyd Wright and Le Corbusier". in Kim Williams (ed.), Nexus VII, Architecture and Mathematics, Turin: KW Books and Birkhauser.

Pfeiffer, B, B. (1988). Frank Lloyd Wright Monograph 1951-1959, Vol. 8. Tokyo: A.D.A EDITA.

Pfeiffer, B, B. (2002). Frank Lloyd Wright: Elegant Houses. Edited by Yukio Futagawa.Vol. 006. Tokyo: A.D.A. EDITA.

Pfeiffer, Bruce Brooks. 2004. Frank Lloyd Wright, 1867-1959. Koln: Taschen

Pyron, B. "Wright's Diamond Module Houses: his development of non-rectalinear interior space" Art Journal Vol 21,2 Winter 1961-1962, 92-96.

Stamps, A, E. III (2002). "Fractals, Skylines, Nature and Beauty," Landscape and Urban Planning, 60(3), 163-184

Storrer, W, A. (1979). The Architecture of Frank Lloyd Wright: A Complete Catalogue. 2nd ed. Cambridge, Massachusetts: MIT Press.

Storrer, W, A. (1993). The Frank Lloyd Wright Companion. Chicago: University of Chicago Press.

Thomson, I. (1999). Frank Lloyd Wright : A Visual Encyclopedia. London: PRC.

Vaughan, J and M.J Ostwald. (2008). "Approaching Euclidean Limits: A Fractal Analysis of the Architecture of Kazuyo Sejima" in N. Gu, L. F. Gul, M. J. Ostwald and A. Williams. (eds), ANZASCA 08: Innovation Inspiration and Instruction: New Knowledge in the Architectural Sciences. ANZSACA, Newcastle, 285-294.

Wright, F. L. (1954). In the Nature of Materials: Integrity. In On and By Frank Lloyd Wright: A primer of architectural principles. (2005) New York: Phaidon Press Limited.

\section{About the Authors}

Josephine Vaughan

Josephine Vaughan is a research higher degree candidate at the University of Newcastle, where she is also a member of the architectural computing research group. Her postgraduate studies are focused on the fractal dimensions of buildings. Josephine's architectural designs have been exhibited and installed regionally and nationally.

\section{Prof. Michael J. Ostwald}

Professor Michael J. Ostwald is Dean of Architecture at the University of Newcastle, Australia, a Visiting Professor at RMIT University (Melbourne) and a Professorial Research Fellow at Victoria University Wellington.He has a PhD in architectural history and theory and a higher doctorate (DSc) in the mathematics of design. He has lectured in Asia, Europe and North America and has written and published extensively on the relationship between architecture, philosophy and geometry. Michael Ostwald is a member of the editorial boards of the Nexus Network Journal and Architectural Theory Review and he is co-editor of the journal Architectural Design Research. 